\title{
Penentuan Awal Ramadhan, Syawal dan Dzulhijjah Perspektif Tareqat Naqshabandiyah Al-Khalidiyah Al-Jalaliyah
}

\author{
Deniansyah Damanik $^{{ }^{*}}$, Putri Ramadhani Rangkuti ${ }^{2}$ \\ ${ }^{1,2}$ Universitas Islam Negeri Sumatera Utara \\ ${ }^{1 *}$ Email: deniansyahdamanik@gmail.com
}

\begin{abstract}
Tareqat Naqshabandiyah Al-Khalidiyah Al-Jalaliyah Kec. Bandar Masilam, Simalungun, North Sumatra Province in determining the beginning of Ramadan, Syawal and Dzulhijjah has its own method, namely Hisab Qomariyah and Mursyid Decision. In this study we can find out how the method used by Tareqat Naqshabandiyah AlKhalidiyah Al-Jalaliyah, as well as a treasure trove of knowledge on the determination of the beginning of Ramadan, Syawal and Dzulhijjah, Tareqat Naqshabandiyah Al-Khalidyah Jalaliyah is often different from the government of the Republic of Indonesia.

Keywords : Naqshabandiyah Al-Khalidiyah Al-Jalaliyah, Hisab Qomariyah
\end{abstract}

\section{Abstrak}

Tareqat Naqshabandiyah Al-Khalidiyah Al-Jalaliyah Kec. Bandar Masilam Kab. Simalungun Prov. Sumatera Utara dalam menentukan Awal Ramadhan, Syawal dan Dzulhijjah memiliki metode tersendiri yaitu Hisab Qomariyah dan Keputusan Mursyid. dalam penelitian ini kita bisa mengetahui bagaimana metode yang digunakan oleh Tareqat Naqshabandiyah Al-Khalidiyah Al-Jalaliyah tersebut, serta menjadi khazanah keilmuan mengenai penentuan awal Ramadhan, Syawal dan Dzulhijjah, Tareqat Naqshabandiyah Al-Khalidyah Jalaliyah ini kerap kali berbeda dengan pemerintah Republik Indonesia.

Kata Kunci : Naqshabandiyah Al-Khalidiyah Al-Jalaliyah, Hisab Qomariyah

\section{Artikel Info}

Received:

02 Januari 2021

Revised:

23 Maret 2021

Accepted:

23 April 2021

Published:

08 Juni 2020 


\section{AL-MARSHAD: JURNAL ASTRONOMI ISLAM DAN ILMU-ILMU BERKAITAN \\ ISSN 2442-5729 (print) || ISSN 2598-2559 (online) \\ http://jurnal.umsu.ac.id/index.php/almarshad \\ DOI: //doi.org/10.30596/jam.v7i1.5858 | Vol. 7, No. 1 Juni 2021}

\section{A. Pendahuluan}

Umat Islam memiliki momen, tanggal dan waktu - waktu penting didalam sebuah ibadah seperti menentukan 1 Ramadhan, Syawal \& Dzulhijjah. Hal ini terbilang sangat krusial dikarenakan penetapan - penetapan tersebut akan membawa point tersendiri di dalam menjalankan sebuah ibadah. Seperti 1 Ramadhan, Syawal, \& Dzulhijjah. 1 Ramadhan merupakan momen yang menentukan kapan akan dimluainya waktu melaksanakan rukun Islam yang ke-4 yaitu berpuasa. 1 Syawal merupakan hari dimana kemenangan umat Islam merayakan Idul Fitri, hari yang penuh berkah dan saling maafmemaafkan. 1 Dzulhijjah hari dimana waktu memasuki rukun Islam yang ke-5 yaitu ibadah Haji

Didalam Al Quran Allah melukiskan tentang adanya tanda - tanda waktu bagi manusia, sebagaimana dalam surah AlBaqarah (2) : 189.

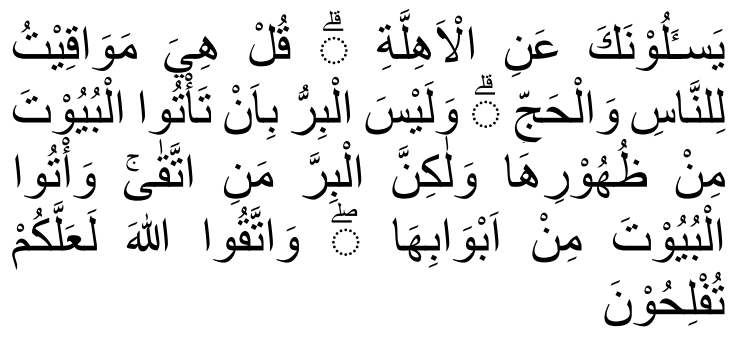

Artinya : 'Mereka bertanya kepadamu

1 Wahbah Az-Zuhaili, Tafsir Al Wasith (Al Fatihah - At Taubah, Alih Bahasa Muhtadi (Jakarta: Gema Insani, 2012). tentang hilal (bulan sabit). Katakanlah 'hilal' (bulan sabit) itu adalah tanda - tanda waktu bagi manusia dan (ibadah) Haji. Dan bukanlah kebajikan memasuki rumah rumah dari belakangnya, akan tetapi kebajikan itu ialah kebajikan orang yang bertaqwa. Dan masuklah ke rumah- rumah itu dari pintunya dan bertaqwalah kepada Allah agar kamu beruntung (Al-Baqarah /2 : 189).

Wahbah Az-Zuhaili menjelaskan tentang sebab turunnya ayat ini, bahwa Ibnu Abbas berkata,',ayat ini turun ketika segolongan kaum muslimin bertanya kepada Nabi tentang hilal, apa faedah peredarannya, kesempurnaannya, dan perbedaannya dengan matahari." Allah menjawab pertanyaan ini dengan menjelaskan faedah dan sebab sebab perkembangan yang melaluinya. Yaitu untuk menentukan waktu dan menghitung hari sehingga bisa diketahui waktu jatuh tempo hutang, waktu pelaksanaan akad, tanggal pelunasan sewa, waktu berakhirnya iddah bagi perempuan, dan sebagainya yang berkaitan dengan kemaslahatan manusia. Perjalanan bulan yang menjadi acuan dalam penentuan awal bulan Qomariyah, dianggap mudah dalam menghitung dan sesuai dengan Bangsa Arab. ${ }^{1}$

Di dalam Tafsir Ruhul Ma'ani bahwa kata "الاهلة" merupakan bentuk jamak dari kata "هلال". 2. Di dalam Tafsir Ibnu Katsir

${ }^{2}$ Syihabuddin Sayyid Mahmud Al-Alusi AlBaghdadi, Tafsir Ruhul Ma'ani (Beirut: Dar Al Kitab Al Amaliyah). 


\section{AL-MARSHAD: JURNAL ASTRONOMI ISLAM DAN ILMU-ILMU BERKAITAN \\ ISSN 2442-5729 (print) || ISSN 2598-2559 (online) \\ http://jurnal.umsu.ac.id/index.php/almarshad \\ DOI: //doi.org/10.30596/jam.v7i1.5858 | Vol. 7, No. 1 Juni 2021}

dijelaskan bahwa telah berkata $\mathrm{Al}$ - Aufi dari Ibnu Abbas seorang manusia bertanya kepada Rasulullah SAW tentang hilal maka turunlah ayat "Yas alunaka 'Anil Ahillah Qul Hiya Mawaqyytu linnasi Wal Hajji'”. Dengan hilal itu mereka melakukan perbuatan tentang suatu keadaan agama mereka, seperti iddah bagi perempuan mereka dan ibadah Haji. ${ }^{3}$

Pada ayat ini bisa kita pahami bahwasannya hilal merupakan suatu tanda tanda waktu bagi manusia. Hal ini sebagaimana yang dijelaskan para mufassirin diatas, bahkan hal ini menyangkut perihal hablum minallah tentang ibadah,oleh karena itu manusia bisa mengetahui waktu - waktu untuk melakukan sebuah ibadah kapan dimulai, berkahir serta batas - batasannya. Selain daripada itu Terdapat dua benda angkasa yang peredarannya mempengaruhi waktu dibumi, yakni matahari dan bulan. ${ }^{4}$

Keduanya memiliki manzilahmanzilah (orbit/garis edar) yang dimanfaatkan oleh manusia sebagai patokan waktu, hari, bulan, bilangan tahun, dan sebagainya dengan perhitungan perhitungan tertentu atau yang disebut dengan penanggalan. ${ }^{5}$ Penanggalan dalam literatur disebut dengan tarikh,takwim \&

\footnotetext{
${ }^{3}$ Ismail ibnu Katsir Al Quraysi Ad - Dimasqy, Tafsir Ibnu Katsir (Beirut: Dar Al Fikri, Jilid.I).

${ }^{4}$ Hendro Setyanto, Membaca Langit (Jakarta: Al Ghurabi, 2008).
}

almanak. ${ }^{6}$ Yang merupakan sebuah sistem pengorganisasian waktu untuk perhitungan selama priode tertentu.

Penentuan awal bulan Hijriyah, khususnya Ramadhan, Syawal \& Dzulhijjah sangat penting bagi umat Islam karena berkaitan dengan ibadah syar'I terutama Ramadhan. Namun praktik yang terjadi dilapangan pemerintah dalam hal ini kementrian agama selalu mengadakan sidang istbath di akhir bulan Sya'ban untuk awal Ramadhan, akhir bulan Ramadhan untuk bulan Syawal, dan akhir bulan Dzulqa'dah di awal bulan bulan Dzulhijjah. Oleh karena itu seringkali hal ini mengakibatkan keresahan kepada masyarakat sebab masyarakat ketika akan menjalankan puasa atau akan mengakhiri puasa masih menunggu pihak pemerintah dalam menggelar sidang istbaht di akhir bulan Sya'ban untuk awal Ramadhan, akhir bulan Ramadhan di awal bulan Syawal dan akhir bulan Dzulqa'dah di bulan Dzulhijjah. Hal ini tidak menutup kemungkinan terjadi perbedaan penentuan dan penetapan awal bulan Ramadhan, Syawal \& Dzulhijjah sekalipun pemerintah telah menyatukan umat Islam Indonesia lewat lewat sidang istbaht tersebut. Apalagi

\footnotetext{
Moedji Raharto, Sistem Penanggalan Syamsyiah/Masehi (Bandung: ITB, 2000).

6 Susiknan Azhari, Ilmu Falak (Perjumpaan Khazanah Islam Dan Sains Modern (Yogyakarta: Suara Muhammadiyah, 2004).
} 


\section{AL-MARSHAD: JURNAL ASTRONOMI ISLAM DAN ILMU-ILMU BERKAITAN \\ ISSN 2442-5729 (print) || ISSN 2598-2559 (online) \\ http://jurnal.umsu.ac.id/index.php/almarshad \\ DOI: //doi.org/10.30596/jam.v7i1.5858 | Vol. 7, No. 1 Juni 2021}

pelaksanaan sidang istbaht yang dilakukan pemerintah itu cukup memicu umat Islam Indonesia galau dalam menjalankan Ibadah karena harus menunggu keputusan pemerintah yang baru dapat diperoleh keputusan tersebut menjelang pelaksanaan sholat tarawih sehingga ini bagian dari persoalan bagi umat Islam Indonesia. Belum lagi sistem penanggalan Hijriyah yang mempunyai banyak sistem dan konsep sehingga akhirnya masyarakat menjadi berbeda dalam menjalankan ibadah puasa tersebut yang hal ini pada umumnya masyarakat hanya mengetahui bahwa perbedaan penetapan bulan Qamariyah disebabkan karena adanya hisab dan rukyat. Tetapi ada juga penyebab lain yaitu adanya perbedaan intern dikalangan ahli hisab dan rukyat itu sendiri. ${ }^{7}$

Selain daripada itu pemerintah Indonesia ada membuat sebuah lembaga yang bertugas menyatukan seluruh umat Islam Indonesia dalam penentuan awal Ramadhan dan hari raya di Indonesia yaitu adalah Badan Hisab Dan Rukyah (BHR) Kementrian Agama Republik Indonesia (KEMENAG). Majelis Ulama Indonesia memutuskan

7 Jaenal Arifin, 'Dialektika Hubungan Ilmu Falak Dan Penentuan Awal Ramadhan, Syawal, Dzulhijjah Di Indoensia (Sinergi Antara Independensi Ilmuan Dan Otoritas Negara)', Jurnal Penelitian, 13.1 (2019), 40-41.

8 Faisal Yahya Yacob dan Faisal Ahmad Shah, 'Metode Penentuan Awal Ramadhan Dan Hari tentang penetapan awal Ramadhan, Syawal \& Dzulhijjah, No. 2 Tahun 2004 memberikan otoritas kepada pemerintah yaitu Kementrian Agama sebagai lembaga resmi dalam penetapan awal Ramadhan dan hari raya serta memerintahkan kepada seluruh umat Islam untuk mengikuti ketetapan pemerintah tersebut. $^{8}$

Organisasi - organisasi Islam di Indonesia terutama Muhammadiyah dan NU ketika berintraksi dengan persoalan kalender Hijriyah telah berkiprah dan memberi corak sesuai doktrin yang dimiliki, khususnya dalam penetapan awal bulan Ramadhan, Syawal \& Dzulhijjah. ${ }^{9}$ Banyaknya organisasi - organisasi kemasyarakatan Islam di Indonesia juga menjadi salah satu pembeda tentang penetapan awal bulan Ramadhan, Syawal \& Dzulhijjah. Seperti NU, Muhammadiyah, Al Washliyah, PERSIS (Persatuan Islam), PERTI (Persatuan Tarbiyah Islamiyah), An-Nadzir, Naqsyabandiyah, HTI, Jamaah Muslimin, dan Nahdatul Wathan serta Dewan Dakwah Islamiyah.

Di Indonesia tepatnya di Sumatera Utara ada kelompok keagamaan yang masih

Raya Menurut Ulama Dayah Aceh', Jurnal Ilmiah Islam Futura, 15.1 (2016), 11.

${ }^{9}$ Susiknan Azhari, Kalender Islam Ke Arah Integrasi Muhammadiyah - NU (Yogyakarta: Museum Astronomi Islam, 2012). 


\section{AL-MARSHAD: JURNAL ASTRONOMI ISLAM DAN ILMU-ILMU BERKAITAN \\ ISSN 2442-5729 (print) || ISSN 2598-2559 (online) \\ http://jurnal.umsu.ac.id/index.php/almarshad \\ DOI: //doi.org/10.30596/jam.v7i1.5858 | Vol. 7, No. 1 Juni 2021}

memiliki corak perbedaan sendiri mengenai penetapan Awal Ramadhan, Syawal \& Dzulhijjah. Yaitu adalah Tareqat Naqshabandiyah Kholidiyah Jalaliyah Kec. Bandar Masilam Kab. Simalungun. Pada tahun 2018, Majelis Fatwa Tareqat Naqshabandiyah Kholidiyah Jalaliyah melaksanakan 1 Syawal pada tanggal 13 Juni 2018 bertepatan pada 1 Syawal 1439 Hijriyah di Aula Pondok Pesantren Bandar Tinggi Kec. Bandar Masilam Kab. Simalungun yang kala itu Tareqat Naqshabandiyah Kholidiyah Jalaliyah dipimpin oleh Buya Dr. Syekh Salman Daim. Hal itu memiliki perbedaan waktu selama 2 hari, dimana pemerintah Indonesia pada sidang istbaht pada tahun 2018 menetapkan 1 Syawal pada tanggal 15 Juni 2018 bertepatan 1 Syawal 1439 Hijriyah.

Oleh karena itu hal ini menarik di kaji mengingat Tareqat Naqshabandiyah AlKhalidiyah Al-Jalaliyah Kec. Bandar Masilam Kab. Simalungun juga memiliki banyak pengikut dan memiliki metode tersendiri dalam menentukan awal Ramadhan, Syawal dan Dzulhijjah.

Tareqat Naqshabandiyah

AlKhalidiyah Al-Jalaliyah bertempat di Desa Bandar Tinggi Kec. Bandar Masilam Kab. Simalungun Prov. Sumatera Utara, dibangun oleh Syekh Dr. Salman Daim. Syekh Dr. Salman Daim lahir pada 01 Januari 1942, istri beliau bernama Rohani Silalahi. Syekh Dr.
Salman Daim alumni Madrasah Al-Qismul Aly Al-Washliyah Perbaungan Kab. Serdang Bedagai Prov. Sumatera Utara. Wafat pada hari senin, 15 Oktober 2018, akan tetapi di batu nisan beliau tertulis mangkatnya pada tanggal 16 Otober, meninggal jam 8 pagi di Pekanbaru Riau pada umur 78 tahun dan dikuburkan di Pusat Tareqat Naqshabandiyah Al-Khalidiyah Al-Jalaliyah Kec. Bandar Masilam SUMUT.

Tareqat Naqshabandiyah Khalidiyah Jalaliyah Desa Bandar Tinggi Kec. Bandar Masilam Kab. Simalungun memiliki ajaran 17 maqom tingkatan, yaitu: 1) Zikir Ismu Zat,

2) Zikir Lathaif, 3) Zikir Nafi Isbat, 4) Zikir Wukuf, 5) Muraqabah Muthlaq, 6) Muraqabah Ahadiyatul Af'al, 7) Muraqabah Ma'iyah, 8) Muraqabah Aqrobiyah, 9) Muraqabah Ahadiatuz Zat, 10) Muraqabah Zatussorfi Wal Bukhti, 11) Maqam Musyahadah, 12) Maqam Muqabalah, 13) Maqam Mukassyafah, 14) Maqam Mukafahah, 15) Maqam Fana Fillah, 16) Maqam Baqa Billah, 17) Maqam Jama' Unshu Billah.

Sedangkan silsilah Tareqat Naqshabandiyah Khalidiyah Al-Jalaliyah yaitu: 1) Nabi Muhammad SAW, 2) Sayyidina Abu Bakar Siddiq, 3) Salman AlFarisi, 4) Qasim bin Muhammad bin Abu Bakar Siddiq, 5) Imam Ja'far Shadiq, 6)Abuya Yazid Al-Bustami, 7) Abu Hasan Al-Kharqani, 8) Abu Ali Parmadi, 9) Syekh Yusuf Hamdani, 10) Syekh Abdul Khaliq 


\section{AL-MARSHAD: JURNAL ASTRONOMI ISLAM DAN ILMU-ILMU BERKAITAN \\ ISSN 2442-5729 (print) || ISSN 2598-2559 (online) \\ http://jurnal.umsu.ac.id/index.php/almarshad \\ DOI: //doi.org/10.30596/jam.v7i1.5858 | Vol. 7, No. 1 Juni 2021}

Pajduwani, 11) Syekh Arif Riyukuri, 12) Syekh Mahmud Anjiri, 13) Syekh Ali Rami Thani, 14) Syekh Muhammad Babassamasi, 15) Syekh Amir Kulali, 16) Syekh Bahauddin Naqsyabandi, 17) Syekh Muhammad Alauddin Al-Athari, 18) Syekh Ya'kub Jarkhi Khasyari, 19) Syekh Abdullah Ahrari Samarqandi, 20) Syekh Muhammad Zahidi, 21) Syekh Darwisy Muhammad, 22) Syekh Muhammad Khauzaki Al-Amkanaki, 23) Syekh Muhammad Baqi Billah, 24) Syekh Ahmad Faruqi Sarhindi, 25) Syekh Muhammad Ma'shum, 26) Syekh Syaifuddin, 27) Syekh Nur Muhammad Badawani, 28) Syekh Syamsuddin Janjanani, 29) Syekh Abdullah Dahlawi, 30) Maulana Syekh Khalid Qurdi, 31) Syekh Abdullah Afandi, 32) Syekh Sulaiman Qurmi, 33) Syekh Sulaiman Zuhdi, 34) Syekh Ali Ridha, 35) Prof. Dr. Syekh H. Jalaluddin, 36) Dr Syekh Salman Daim, 37) Dr. Syekh M. Nur Ali S.Ag M.Hum.

Adapun tujuan penelitian ini, untuk mengetahui metode penentuan awal Ramadhan, Syawal dan Dzulhijjah Tareqat Naqshabandiyah Khalidiyah Al-Jalaliyah Kec. Bandar Masilam Kab. Simalungun Prov. Sumatera Utara. selain daripada itu manfaat dari penelitian ini adalah memberikan penjelasan kepada masyarakat tentang metode penentuan awal Ramadhan, Syawal dan Dzulhijjah Tareqat Naqshabandiyah Al-
Khalidiyah Al-Jalaliyah, serta memberikan sumbangsih khazanah keilmuan tentang disiplin ilmu falak.

\section{B. Metode Penelitian}

Jenis penelitian ini merupakan penelitian sosiologis dan empiris. Penelitian sosiologis merupakan bagian dari penelitian dalam bidang ilmu-ilmu social. Soerjono Soekanto mengatakan bahwa penelitian sosiologis merupakan suatu proses pengungkapan kebenaran berdasarkan penggunaan konsep-konsep dasar yang dikenal dalam sosiologi. Konsep-konsep dasar tersebut berfungsi sebagai sarana ilmiah dalam rangka mengungkapkan kebenaran yang terdapat dalam kehidupan masyarakat. Adapun beberapa konsep dasar yang dimaksudkan antara lain adalah kelompok sosial, kemajemukan social, kekuasaan dan wewenang, masalah sosial, perubahan social, dll. Sedangkan empiris.yaitu suatu pengelompokan ilmu pengetahuan yang mengkhusukan dalam penelitian prilaku manusia dan lingkungannya.

\section{Hasil dan Pembahasan}

\section{Dasar Hukumnya}

Tareqat Naqshabandiyah Khalidiyah Jalaliyah mendasarkan pendapatnya kepada firman Allah, sebagai berikut :

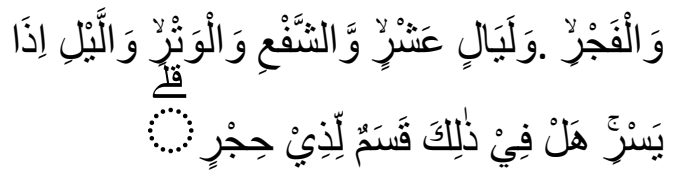




\section{AL-MARSHAD: JURNAL ASTRONOMI ISLAM DAN ILMU-ILMU BERKAITAN \\ ISSN 2442-5729 (print) || ISSN 2598-2559 (online) \\ http://jurnal.umsu.ac.id/index.php/almarshad \\ DOI: //doi.org/10.30596/jam.v7i1.5858 | Vol. 7, No. 1 Juni 2021}

Artinya : Demi Fajar. Demi sepuluh malam yang dimuliakan. Demi bilangan yang genap dan yang ganjil. Demi malam yang gilir berganti. Bukankah dalam benda-benda itu ada isyarat yang menyakinkan bagi orang yang berakal. (Q.S. Al-Fajr:1-5).

Tareqat Naqshabandiyah Khalidiyah Jalaliyah dalam memahami ayat 3 surah AlFajr ini ialah ketentuan bilangan dan jumlah hari dalam satu bulan, yaitu hitungan ganjil dan genap. ganjil hitungannya 29 hari dan genap ialah 30 hari. Hal ini diterapkan untuk bulan Muharram 30 hari, untuk Safar 29 hari, untuk bulan Rabiul Awal 30 hari dan seterusnya.

Selain itu Tareqat Naqshabandiyah Khalidiyah Jalaliyah juga mendasarkan kepada ayat :

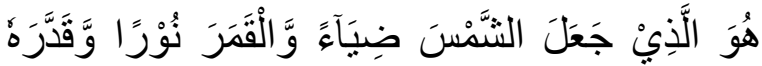

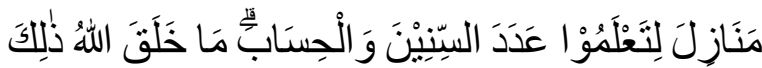

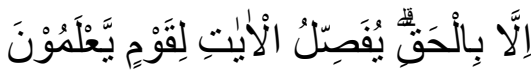

Artinya : dialah yang menjadikan matahari bersinar dan bulan bercahaya dan ditetapkannya manzilah- manzilah (tempattempat) bagi perjalanan bulan itu. Supaya kamu mengetahui bilangan tahun dan perhitungan (waktu). Allah tidak menciptakan yang demikian itu melainkan dengan hak. Dia menjelaskan tanda-tanda (kebesarannya) kepada orang yang mengetahui. (Q.S. Yunus : 5).

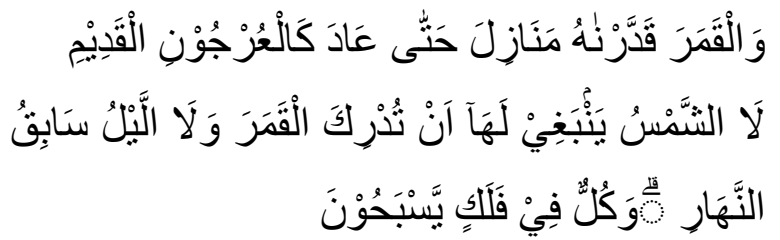

Artinya : dan telah kami tetapkan bagi bulan manzilah-manzilah, sehingga (setelah dia sampai ke manzilah yang terakhir) kembalilah dia sebagai bentuk tandan yang tua. Tidaklah mungkin bagi Matahari mendapatkan Bulan dan malampun tidak dapat mendahului siang. Dan masing-masing beredar pada garis edarnya. (Q.S. Yasin :3940).

Tareqat Naqshabandiyah Khalidiyah Jalaliyah juga selain menyandarkan kepada Al-Quran juga kepada Hadis-Hadis Nabi. :

$$
\begin{aligned}
& \text { وعن ابن عمررضي الله عنهما قال : سمعت } \\
& \text { رسول الله ص.م. يقول : اذا رايتموه فصوموا } \\
& \text { و اذا رايتموه فافطرو ا فان غم عليكم فاقدرو اله. } \\
& \text { (متفق عليه) }
\end{aligned}
$$

"'artinya : dari Ibnu Umar radiallahu anhuma telah berkata ia : aku pernah mendengar Rasulullah bersabda : bila kamu telah melihat tanggal satu bulan ramadhan, maka berpuasalah, dan apabila kamu melihat tanggal satu syawal maka berhari rayalah. Tetapi bila terlihat mendung, maka perkirakanlah. (Hadist disepakati oleh Imam Bukhari dan Imam Muslim).

$$
\begin{aligned}
& \text { لا تصومو ا حتى ترو الههلال و لاتفطروا حتى تروه } \\
& \text { فان غم عليكم فاقدرواله }
\end{aligned}
$$

'artinya : janganlah kamu berpuasa sebelum kamu melihat hilal (Ramadan) dan janganlah kamu berbuka sebelum kamu melihat hilal (syawal). Jika tertutup atas kalian maka takdirkanlah. (HR. Muslim dan Ibnu Umar) 


\section{Metodenya}

\section{a. Hisab Qomariyah}

Hisab Qomariyah menjadi metode penentuan Awal Ramadhan, Syawal dan Dzulhijjah Tareqat Naqshabandiyah Khalidiyah Jalaliyah. Hal ini yang diajarkan oleh Syekh Dr. Salman Daim. Sebelumnya mengenai pemahaman terhadap surah Al-Fajr ayat 3 bahwa bulan pertama yaitu bulan Muharam 30 hari, kemudian Safar 29 hari. dan untuk Ramdahan 30 hari, perhitungan ini terus menerus sampai hari kiamat. hal ini berbeda jika pada bulan Dzulhijjah,yaitu tidak selalu 29 hari, akan tetapi bisa 30 hari hal ini mengacu kepada tahun tersebut masuk kepada tahun kabisat atau basithah. Berikut ini nama dan jumlah hari pada bulan-bulan hijriyah yang ditunjukkan oleh Tabel 1. dibawah ini :
Tabel 1. Nama bulan dan jumlah hari

\begin{tabular}{lll}
\hline No & Nama Bulan & $\begin{array}{l}\text { Panjang } \\
\text { Hari }\end{array}$ \\
\hline 1 & Muharram & 30 Hari \\
\hline 2 & Shafar & 29 Hari \\
\hline 3 & Rabiul Awal & 30 Hari \\
\hline 4 & Rabiul Akhir & 29 Hari \\
\hline 5 & Jumadil Awal & 30 Hari \\
\hline 6 & Jumadil Akhir & 29 Hari \\
\hline 7 & Rajab & 30 Hari \\
\hline 8 & Sya'ban & 29 Hari \\
\hline 9 & Ramadhan & 30 Hari \\
\hline 10 & Syawal & 29 Hari \\
\hline 11 & Zulqa'dah & 30 Hari \\
\hline 12 & Zulhijjah & 29/30 Hari \\
\hline
\end{tabular}

Dalam hal penentuan Penentuan awal Ramdhan, Syawal dan Dzulhijjah Tareqat Naqshabandiyah Khalidiyah Jalaliyah sudah mengetahui tahun depan 1 Ramadhan jatuh pada hari apa dan 1 Syawal jatuh pada hari apa, serta 1 Dzulhijjah jatuh pada hari apa. Hal ini dikarenakan Hisab Qomariyah yang mereka yakini.

Hisab Qomariyah berarti perhitungan bulan. ${ }^{10}$ Hisab Qomariyah ini patokannya adalah hari. Oleh karena itu awal Ramadhan, Syawal dan Dzulhijjah tahun depan sudah diketahui jatuhnya pada hari apa berdasarkan Hisab Qomariyah.

\section{a). Menentukan Awal Ramadhan}

untuk penentuan awal Ramadhan tahun depan yaitu tambahkan 2 hari dari hari raya sebelumnya.

10 Wawancara dengan Syekh Tajuddin, 'Pada Tanggal 03 Agustus 2020 M.' 


\section{AL-MARSHAD: JURNAL ASTRONOMI ISLAM DAN ILMU-ILMU BERKAITAN \\ ISSN 2442-5729 (print) || ISSN 2598-2559 (online) \\ http://jurnal.umsu.ac.id/index.php/almarshad \\ DOI: //doi.org/10.30596/jam.v7i1.5858 | Vol. 7, No. 1 Juni 2021}

\section{Rumus Pertama :}

HRIFTS (Hari Raya Idul Fitri Tahun Sebelumnya) + 2 HARI

Contoh : Kalau hari raya idul fitri tahun sebelumnya jatuh pada hari senin, maka awal Ramadhan tahun depan adalah hari Rabu.

(Senin - Selasa - Rabu).

\section{Rumus Kedua :}

ARTH (Awal Ramadhan Tahun Sebelumnya) +5 Hari (Awal Perhitungan 5 Hari itu Termasuk Hari Awal Ramadhan Sebelumnya).

Contoh : Kalau hari 1 Ramadhan tahun sebelumnya hari Rabu maka 1 Ramadhan tahun depan jatuh pada hari minggu.

(Rabu - Kamis - Jumat - Sabtu - Minggu).

\section{b). Menentukan Awal Syawal}

untuk menentukan Awal Syawal, Tareqat Naqshabandiyah Khalidiyah Jalaliyah selalu menggenapkan bulan Ramadhan selama 30 hari.

\section{Rumus Pertama :}

(Bulan Ramadhan digenapkan 30 Hari / Hitung Saja 30 Hari dari Jatuhnya Awal Ramadhan, dan Hari yang ke-31 nya Otomatis jatuhnya Awal Syawal / Idul Fitri).

\section{Rumus Kedua :}

11 Wawancara dengan Syekh Ruslan, 'Pada Tanggal 26 Juli 2020 M'.
ARTT (Awal Ramadhan Tahun Tersebut) +2 Hari

Contoh : kalaulah awal Ramadhan pada tahun tersebut jatuh pada hari kamis, maka awal Syawal / 1 Syawal jatuh pada hari sabtu. ${ }^{11}$ (Kamis - Jumat - Sabtu).

\section{c). Menentukan Awal Dzulhijjah}

Mengenai Awal Dzulhijjahnya, Tareqat Naqshabandiyah Khalidiyah Jalaliyah menggunakan perhitungan dari bulan Ramadhan 30 Hari, Syawal 29 Hari, Dzulqo'dahnya 30 Hari. Akan tetapi Tareqat Naqshabandiyah Khalidiyah Jalaliyah sudah mengetahui hari apa jatuhnya 10 Dzulhijjah (Ibadah Haji). Ini dikarenakan Hisab Qomariyah mereka.

\section{Rumus :}

HRIATT (Hari Raya Idul Adha Tahun Tersebut) sama harinya dengan HRIFTT (Hari Raya Idul Fitri Tahun Tersebut).

Contoh : kalau satu Ramadhan jatuh pada hari sabtu, maka 10 Dzulhijjah juga jatuh pada hari sabtu.

\section{Keputusan Mursyid}

Tareqat Naqshabandiyah Khalidiyah Jalaliyah meskipun memiliki perhitungan sendiri yaitu Hisab Qomariyah, akan tetapi itu hanya bisa bersifat sementara. Hal ini dikarenakan keputusan awal Ramadhan diserahkan seluruhnya kepada Mursyid. hal 


\section{AL-MARSHAD: JURNAL ASTRONOMI ISLAM DAN ILMU-ILMU BERKAITAN \\ ISSN 2442-5729 (print) || ISSN 2598-2559 (online) \\ http://jurnal.umsu.ac.id/index.php/almarshad \\ DOI: //doi.org/10.30596/jam.v7i1.5858 | Vol. 7, No. 1 Juni 2021}

ini terkadang menjadikan yang berdasarkan perhitungan Hisab Qomariyah mereka berbeda lebih cepat 2 hari dari pemerintah menjadi 1 hari dari pemerintah.

\section{Kesimpulan}

Tareqat Naqshabandiyah Khalidiyah Jalaliyah Kec. Bandar Masilam Kab. Simalungun dalam menetapkan penentuan awal Ramadhan, Syawal dan Dzulhijjah menggunakan metode Hisab Qomariyah, akan tetapi dalam hal ini juga Mursyid/Pimpinan Tareqat Naqshabandiyah Khalidiyah Jalaliyah juga memiliki hak kewenangan untuk memutuskan kapan jatuhnya satu Ramadhan, Syawal dan Dzulhijjah meskipun berdasarkan perhitungan Hisab Qomariyah sudah ditentukan

\section{Daftar Pustaka}

Faisal Yahya Yacob dan Faisal Ahmad Shah, 'Metode Penentuan Awal Ramadhan Dan Hari Raya Menurut Ulama Dayah Aceh', Jurnal Ilmiah Islam Futura, 15.1 (2016), 11

Hendro Setyanto, Membaca Langit (Jakarta:

Al Ghurabi, 2008)

Ismail ibnu Katsir Al Quraysi Ad - Dimasqy,

Tafsir Ibnu Katsir (Beirut: Dar Al Fikri, Jilid.I)

Jaenal Arifin, 'Dialektika Hubungan Ilmu
Falak Dan Penentuan Awal Ramadhan,

Syawal, Dzulhijjah Di Indoensia (Sinergi Antara Independensi Ilmuan Dan Otoritas Negara)', Jurnal Penelitian, 13.1 (2019), 40-41

Moedji Raharto, Sistem Penanggalan Syamsyiah/Masehi (Bandung: ITB, 2000)

Susiknan Azhari, Ilmu Falak (Perjumpaan Khazanah Islam Dan Sains Modern (Yogyakarta: Suara Muhammadiyah, 2004)

, Kalender Islam Ke Arah Integrasi Muhammadiyah - NU (Yogyakarta:

Museum Astronomi Islam, 2012)

Syihabuddin Sayyid Mahmud Al-Alusi AlBaghdadi, Tafsir Ruhul Ma'ani (Beirut: Dar Al Kitab Al Amaliyah)

Wahbah Az-Zuhaili, Tafsir Al Wasith (Al Fatihah - At Taubah, Alih Bahasa Muhtadi (Jakarta: Gema Insani, 2012)

Wawancara dengan Syekh Ruslan, 'Pada Tanggal 26 Juli 2020 M'

Wawancara dengan Syekh Tajuddin, 'Pada Tanggal 03 Agustus 2020 M.' 